\section{Some differences among figural aftereffects, apparent motion, and paracontrast*}

\author{
ROGER B. HOWARD \\ Colgate University, Hamilton, New York 13346
}

It has been suggested that figural aftereffects, apparent motion, and paracontrast may be produced by very similar or equivalent processes. The empirical functions relating figural aftereffect to the duration of the inspection figure and the interfigural distance are significantly different from the corresponding apparent motion and paracontrast functions. The functions relating paracontrast to the interstimulus interval are significantly different from the corresponding figural-aftereffect and apparent-motion functions. Thus, it is unlikely that the processes underlying the three phenomena are the same. Researchers who attempt to study feature analyzers in the human visual system should consider using more than one dependent variable, since none of the three phenomena contains all of the available information. Within-Ss designs should be avoided because a strong response bias exists between figural-aftereffect and apparent-motion tasks.

Several researchers have suggested that figural aftereffects ${ }^{1}$ and apparent motion may be produced by similar processes (Köhler, 1940, 1965; Köhler \& Wallach, 1944; Detheridge \& Bitterman, 1952; Shapiro, 1954; Christman, 1953; Fehrer \& Ganchrow, 1963). There are three forms of evidence which support this suggestion. First, there is a marked similarity between the functions relating temporal variables to dependent measures of the two phenomena. Fehrer and Ganchrow (1963) measured figural aftereffects while systematically varying the duration of the inspection (I) figure and the interstimulus interval (ISI) over a wide range of values. Although they did not measure apparent motion directly, they pointed out the striking correspondence between the figural-aftereffect functions they obtained for brief durations of the independent variables and those described by Korte's "laws" of apparent motion (cf. Higginson, 1926; McConnell, 1927 ; Neff, 1936; Graham, 1966). Second, the establishment of conditions for figural aftereffects affects the path and the magnitude of apparent motion. Detheridge and Bitterman (1952) reported that the path of a test (T) figure in apparent motion was displaced away from the location previously occupied by an I figure which had been fixated for several seconds. They hypothesized that the aftereffect of the I figure was responsible for the change in apparent motion. Shapiro (1954) found that the magnitude of apparent motion was reduced if its path lay across a region

* This work was supported in part by grants to the author from the Colsate Research Council and from the Sloan Foundation.

undefined. The expert described below were therefore

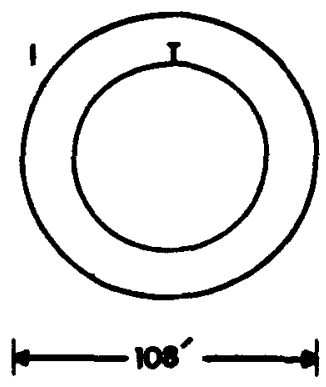

designed to provide information about the two phenomena under equivalent conditions.

\section{EXPERIMENTS 1-3 Method}

Subjects. The Ss were 10 male undergraduates, with normal vision, taking a course in introductory psychology at Colgate University.

Apparatus. The stimuli used in Experiments 1 and 2 were the concentric circles shown in Fig. 1. The outer circle on the left of the configuration was the I figure and was always presented first. The fixation dot and the I figure were drawn in opaque black ink on a white card and shown in the second field of an Iconix three-field tachistoscope. The inner circle on the left and the corresponding circle on the right were the $\mathrm{T}$ and comparison (C) circles, respectively. They were drawn on a second card along with a second fixation dot and were shown in the third field of the tachistoscope, The remaining field, which was used as the forefield, afterfield, and interstimulus field, contained a third white card with only a fixation dot. The spatial configuration produced by illuminating all three fields simultaneously is shown in Fig. 1. The stimuli for Experiment 3 were the same, except that the size of the $T$ and $C$ circles was a variable.

In the figural-aftereffect conditions, the Ss used what will be called the method of recognition, in which they selected a pair of circles from a wall chart which had the same apparent sizes as the $T$ and $C$ circles. This procedure is equivalent to that used by Fehrer and Ganchrow (1963). The chart was made from heavy white posterboard. The alternative pairs of circles were presented in two columns. The left circle in both columns was always $24 \mathrm{~mm}$ in diam and subtended $72 \mathrm{~min}$ of visual arc. In the first column, the diameter of the right
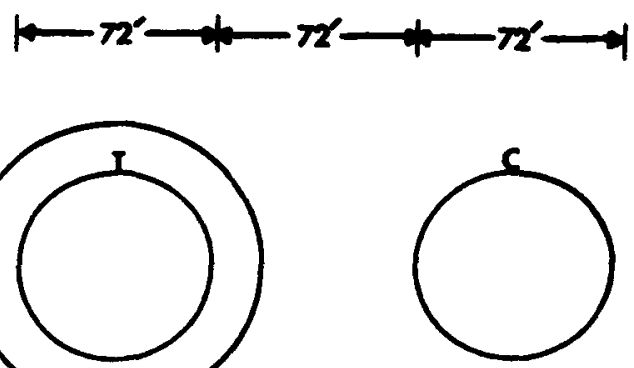
DXPEANENT: 1

RCURAL ATERFFCT TASK

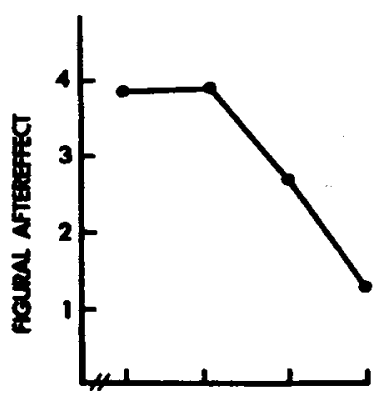

a

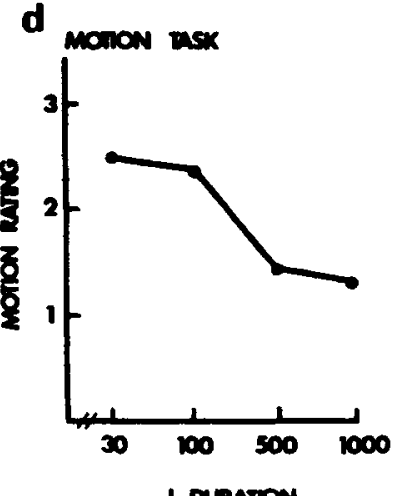

d

I OCRaTion b

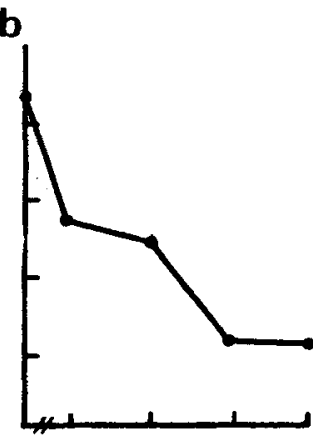

e

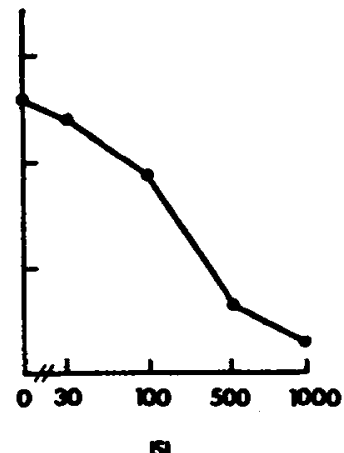

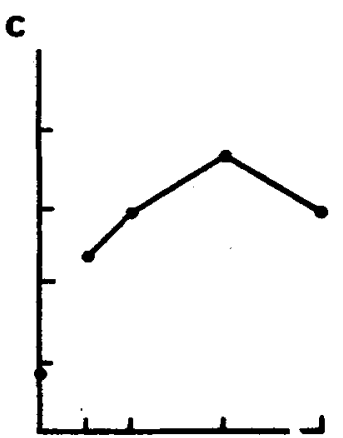

f

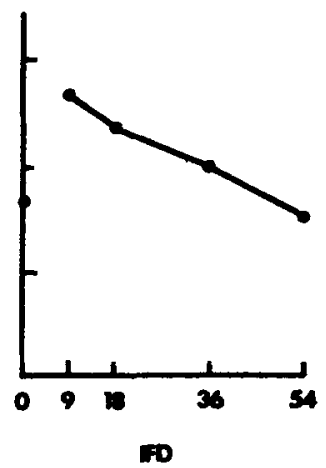

Fig. 2. Mean data from Experiments 1-3. (a-c) The magnitude of the figural aftereffect in minutes of visual arc as a function of the I figure duration, the ISI, and the IFD, respectively. (d-f) The magnitude of apparent motion as a function of the same three variables. I and ISI values are plotted according to the transformation $x^{\prime}=\log _{10} x$, when $x>30$ msec.

circle was reduced by $1 \mathrm{~mm}$ ( $3 \mathrm{~min}$ of arc) in each subsequent pair. In the second column, the right circle was increased by $1 \mathrm{~mm}$ in each subsequent pair.

Design and procedure. The independent variables defining Experiments 1, 2, and 3 were the duration of the I figure $(30,100,500$, and $1,000 \mathrm{msec})$, the ISI $(0,30,100$, 500 , and $1,000 \mathrm{msec}$ ), and the interfigural distance, or IFD $(0,9,18$, 36 , and $54 \mathrm{~min}$ of visual are), respectively. The IFDs were obtained by increasing the diameter of the I circle.

The dependent variables were the amount of apparent motion between the $I$ and $T$ circles and the amount of figural aftereffect as shown by changes in the apparent size of the $T$ circle. The Ss' tasks were to judge the amount of apparent motion on a scale from 0 to 5 (with 0 representing no motion and 5 perfect motion) and the distortion in the size of the $T$ circles by indicating the circles on the wall chart described above which appeared to have the same sizes as the $T$ and $C$ circles.

Since an adequate comparison of the two phenomena requires that figural aftereffects and apparent motion be measured under equivalent conditions, extreme measures were taken to neutralize progressive errors. Each $\mathbf{S}$ saw six lists of trials, two from each experiment. The lists were ordered so that the experiments were counterbalanced over two 1-h sessions for each $S$ and also between pairs of Ss. Each list contained two blocks of figural-aftereffect and two of apparent-motion trials, which were counterbalanced within each list, between each session for each $S$, and randomized across Ss. The levels of the independent variables were counterbalanced within each list and randomized between lists. 2

The first session began with a complete description of the tasks the $S$ was expected to perform. The instructions for the apparent-motion task were identical in all crucial respects to those described by Kahneman (1967) in his study of apparent motion and metacontrast. The instructions for the figural-aftereffect task simply described the task and the use of the wall chart. The $S$ was also encouraged to give his first impression of the phenomenon he was evaluating and to make his response as rapidly as possible.

The first list in each session was preceded by 10 practice trials, 5 selected randomly from each task. The two subsequent lists were preceded by four practice trials, two from each task. The duration of the $T$ and $C$ circles was always $100 \mathrm{msec}$, and the luminance from the white cards was always $21 \mathrm{~mL}$. The IFD was $18 \mathrm{~min}$ of arc in Experiments 1 and 3 , the ISI was 0 in Experiments 1 and 2, and the duration of I was $100 \mathrm{msec}$ in Experiments 2 and 3.

Results and Discussion

Figures 2a-2c show the average figural aftereffect in minutes of visual arc plotted as functions of the duration of the I figure, the ISI, and the IFD. Figures 2d-2f show the average ratings of apparent motion for the corresponding values of the independent variables.

If figural aftereffects and apparent motion are produced by the same processes, then the functions relating the magnitude of each phenomenon to a particular independent variable should be similar. The data from the first two experiments do not contradict this hypothesis. Although there are minor changes in the slopes of the corres ponding figural-aftereffect and apparent-motion functions, none is consistent across the 10 Ss and all have the same sign at corresponding values of the independent variables. The data from Experiment 3, however, show quite different trends. As the IFD is increased from 9 to $54 \mathrm{~min}$, the magnitude of the figural aftereffect tends to increase. In contrast, the amount of motion decreases over the same range of values.

The trends in the six sets of data were formally assessed by six Treatment by Ss analyses of variance (Winer, 1971). The results are shown in Table 1. As can be seen, the changes in all six conditions are significant beyond the .05 level. Duncan's multiple range tests (Winer, 1971) indicate that the trend upward in figural-aftereffect function found in Experiment 3 as the IFD was increased from 9 to $36 \mathrm{~min}$ and the trend downwards in the corresponding apparentmotion function are both significant beyond the .05 level. It is clear from these data that the two phenomena are not equivalent to each other.

Unfortunately, a careful consideration of the data also suggests that there is an extraneous interaction between the two tasks. The results of Experiment 1 show that the figural aftereffect decreases significantly as the duration of the I figure increases. This is in direct contradiction to many 
Table 1

The Results of 15 Treatment by Ss Analyses of $V$ ariance Performed on the Data from Experiments 1-6

\begin{tabular}{|c|c|c|c|c|c|}
\hline \multirow{2}{*}{$\begin{array}{l}\text { Experi- } \\
\text { ment }\end{array}$} & \multirow[b]{2}{*}{ Variable } & \multirow[b]{2}{*}{ Task } & \multicolumn{3}{|c|}{ Mean Squares } \\
\hline & & & Treatment & Error & $\mathbf{F}$ \\
\hline 1 & I Duration & $\begin{array}{l}\text { Figural Aftereffect } \\
\text { Apparent Motion }\end{array}$ & $\begin{array}{l}1.65 \\
3.90\end{array}$ & $\begin{array}{l}0.32 \\
0.81\end{array}$ & $\begin{array}{l}5.12 * * \\
4.81 * *\end{array}$ \\
\hline 2 & ISI & $\begin{array}{l}\text { Figural Aftereffect } \\
\text { Apparent Motion }\end{array}$ & $\begin{array}{r}1.83 \\
11.18\end{array}$ & $\begin{array}{l}0.18 \\
0.52\end{array}$ & $\begin{array}{l}10.14 t \\
21.29+\end{array}$ \\
\hline 3 & IFD & $\begin{array}{l}\text { Figural Aftereffect } \\
\text { Apparent Motion }\end{array}$ & $\begin{array}{l}\mathbf{0 . 3 2} \\
\mathbf{2 . 8 1}\end{array}$ & $\begin{array}{l}0.09 \\
0.24\end{array}$ & $\begin{array}{r}3.31 * \\
11.32+\end{array}$ \\
\hline 4 & I Duration & $\begin{array}{l}\text { Figural Aftereffect } \\
\text { Apparent Motion } \\
\text { Paracontrast }\end{array}$ & $\begin{array}{r}4.84 \\
24.92 \\
1.71\end{array}$ & $\begin{array}{l}0.25 \\
0.99 \\
0.45\end{array}$ & $\begin{array}{r}18.71+ \\
25.06+ \\
3.75 *\end{array}$ \\
\hline $\mathbf{5}$ & ISI & $\begin{array}{l}\text { Figural Aftereffect } \\
\text { Apparent Motion } \\
\text { Paracontrast }\end{array}$ & $\begin{array}{r}3.26 \\
24.54 \\
3.95\end{array}$ & $\begin{array}{l}0.62 \\
0.87 \\
0.51\end{array}$ & $\begin{array}{r}5.26 * * \\
27.89 t \\
7.75 t\end{array}$ \\
\hline 6 & IFD & $\begin{array}{l}\text { Figural Aftereffect } \\
\text { Apparent Motion } \\
\text { Paracontrast }\end{array}$ & $\begin{array}{l}1.51 \\
5.17 \\
4.64\end{array}$ & $\begin{array}{l}0.17 \\
0.65 \\
0.16\end{array}$ & $\begin{array}{r}8.62 t \\
7.85 t \\
28.49 t\end{array}$ \\
\hline
\end{tabular}

$* p<.05 \quad * * p<.01 \quad+p<.001$

studies of figural aftereffects with concentric figures which have shown that the figural aftereffect increases as the I duration is increased to at least $100 \mathrm{msec}$, and often to $5,000 \mathrm{msec}$ and beyond, depending on the conditions used (e.g., Oyama, 1956; Fehrer \& Ganchrow, 1963; Farné, 1965). Although there are many methodological differences between the experiments reported here and these other published reports, the results of posttests with different Ss suggest that there is an interaction between the figural-aftereffect and apparent-motion tasks which has reversed the normal trend in the figural-aftereffect data. Changing the luminance levels, the duration of $T$, ISI, and the IFD does not reverse the trend downward shown in Fig. 2a. However, if the same experimental conditions are used, but the motion task is eliminated, then the posttest data suggest that the figural aftereffect increases as the I duration increases. Thus, the true magnitudes of the motion and figural aftereffect cannot be determined from the results of this set of experiments.

Finally, our Ss reported that the phenomena they observed in Experiment 3 with 0 IFD were qualitatively different from the phenomena in the rest of the study. Since the $I$ and $T$ circles were equal in size, the Ss might be expected to report no apparent motion or figural aftereffect. Instead, many Ss experienced strong apparent motion away from them as if the I circle were suddenly pushed back in space. This was accompanied by apparent shrinkage of the circle. Because the motion was qualitatively quite different from the apparent motion between the $I$ and $T$ figures, many Ss were uncertain about the responses they should make. Three Ss who indicated very strong motion in this condition readily described the phenomenon after completing the experiments. Most of the other Ss could describe the effect and admitted that they were unsure of their responses. Two Ss did not experience the effect at all.

\section{EXPERIMENTS 4-6}

There are a number of different phenomena which frequently occur in conjunction with figural aftereffects and apparent motion. Perhaps the most interesting of these is the "dimming effect" first described by Köhler (1940; Köhler \& Wallach, 1944) and which we now call paracontrast. Köhler observed that the $\mathbf{T}$ figure frequently appeared dimmer than the $C$ figure and that the magnitude of the figural aftereffect and dimming were directly related to the duration of the $I$ figure and inversely related to the ISI and the IFD. Over (1971) has also pointed out the similarities between the conditions under which figural aftereffects and paracontrast occur. Bevan (1951), Nozawa (1956), and Motokawa et al (1957) have reported data which show that the brightness threshold for a small stimulus is closely related to its distance from an area previously stimulated by an I figure. Detheridge and Bitterman (1952) have also noted that a $T$ object in apparent motion through a region previously occupied by an I figure is perceived less clearly.

Most of these authors draw the explicit or implicit conclusion that some subset of figural aftereffect, apparent motion, and paracontrast phenomena may be produced by very similar or equivalent processes. Although their data tend to support this hypothesis, there have been no studies which quantified all three phenomena under equivalent conditions. Experiments 4-6 were therefore designed to provide these data. In order to avoid the interactions found in Experiments 1-3, different $S$ s were used in each of the three tasks.

\section{Method}

Subjects. Fifty-two naive male Ss were selected from the same $S$ pool used in Experiments 1-3. Sixteen Ss served in the figural-aftereffect, 18 in the apparent-motion, and 18 in the paracontrast conditions.

Design and procedure. The design and procedure for Experiments 1-3 and 4-6 were the same, with the following exceptions: Each of the six lists of trials presented to an $S$ in Experiments 4-6 was half the length of a list from Experiments 1-3 because each $S$ performed only one task. The six lists were therefore presented in a single session. The instructions for the paracontrast task were essentially the same as Kahneman's (1967) instructions for metacontrast masking. The $S$ was asked to judge the goodness of paracontrast on a scale from 0 to 5 , with 0 indicating no paracontrast (the $T$ circle was seen very clearly) and 5 indicating perfect paracontrast (the $T$ circle was not seen at all).

\section{Results and Discussion}

Between- us within-Ss design. The results of Experiment 1, in conjunction with the posttest data, suggested that there was an extraneous interaction between the figural-aftereffect and apparent-motion tasks. If an $S$ was required to perform both tasks, the strong apparent motion apparently biased his judgment of the figural aftereffect and actually changed the sign of the function's slope.

There are two ways in which the results of Experiments 4-6 indicate that interactions between the two tasks have been substantially reduced. First. as indicated in Fig. $3 a$, the function relating figural aftereffects to the duration of the I figure has a positive slope in Experiment 4, whereas it was negative in Experiment 1. A Treatment by Ss analysis of variance (Table 1) indicates that the trend upward in the figural aftereffect data is highly significant, as is the trend downward in the data from the corresponding motion conditions shown in Fig. 3d. Duncan's multiple range test also confirms that the trends between conditions with I durations of 100 and $1,000 \mathrm{msec}$ are significant beyond the .05 level for both tasks. These data are compatible with the results of experiments from other laboratories and support the hypothesis that the reverse effect 

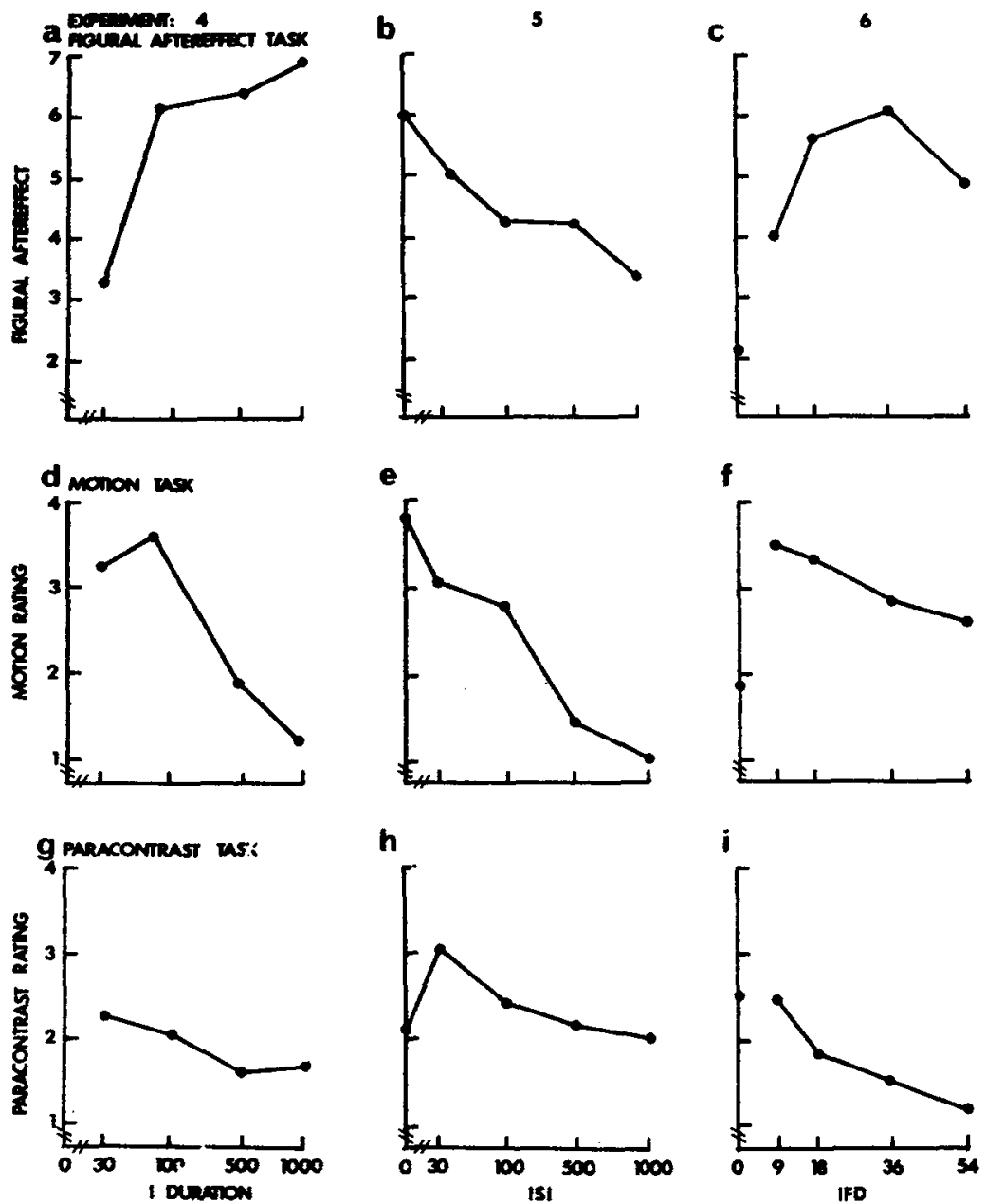

Fig. 3. Mean data from Experiments 4-6. (a-c) The magnitude of the figural aftereffect as a function of the I figure duration, the ISI, and the IFD. (d-f) The magnitude of apparent motion. (g-i) The magnitude of paracontrast as a function of the same three variables.

found in Experiment 1 was the result of an interaction between the tasks. Second, the magnitude of the figural aftereffect and apparent motion have increased in all experiments. The average figural aftereffect has increased from $2.6 \mathrm{~min}$ in Experiments $1-3$ to $4.8 \mathrm{~min}$ in Experiments $4-6$. The average apparent motion has increased from 1.8 to 2.6. Twenty-six of the 28 points shown in Figs. 3a-3f are higher than corresponding points in Fig. 2. The results of six $t$ tests between the average errors for each $S$ in each pair of corresponding experimental tasks (i.e., collapsed across levels of the independent variable) are shown in Table 2. All but one are significant beyond the .05 level, which confirms the above observations. Thus, having Ss judge both figural aftereffect and apparent motion produces serious response biases which can be substantially reduced by using a between-Ss design.
Comparison of

Figural aftereffects and apparent motion. The data shown in Fig. 3 confirm the conclusions from Experiments 1-3 that figural aftereffects and apparent motion are not equivalent to each other. As indicated above, the magnitude of the figural aftereffect in Experiment 4 increase significantly as the duration of the I figure increases, whereas the the Three Phenomena

$* p<.05$

$* * 0<.01$ apparent motion decreases significantly over the same range of values. Figures $3 b$ and $3 e$ show the data from Experiment 5, and Table 1 shows that the trend toward less effect in both tasks as the ISI is increased is significant. Although there are minor differences in the slopes of the curves for figural aftereffeet and apparent motion, as shown in Figs. $3 b$ and $3 e$, these trends are not reliable across the Ss. The trends in Experiment 6 (Figs. $3 c$ and $3 f$; Table 1) are the same as in Experiment 3, but more pronounced. Duncan's multiple range test indicates that the increase in figural aftereffect as the IFD is increased from 9 to $36 \mathrm{~min}$ is significant beyond the .05 level, as is the decrease in the amount of apparent motion over the same range. Although apparent motion and figural aftereffects occur under similar conditions, they do not appear to be equivalent phenomena.

Figural aftereffects and paracontrast. The figural aftereffects in Experiment 4 increase significantly as the I duration is increased, whereas paracontrast decreases significantly over the same range (Figs. $3 \mathrm{a}$ and $3 \mathrm{~g}$; Table 1). In Experiment 5, figural aftereffects decrease significantly as the ISI increases, whereas paracontrast first increases then decreases (Figs. 3b and 3h; Table 1). Although Duncan's test indicates that the increase in paracontrast between 0 and 30 ISI is significant beyond the .05 level, the decrease in the figural aftereffect is not. In Experiment 6, the analyses of variance for both figural aftereffect and paracontrast data are significant (Figs. 3c and 3i; Table 1), and Duncan's test indicates that both the increase in figural aftereffects as the IFD is increased from 9 to $36 \mathrm{~min}$ and the decrease in paracontrast over the same range are significant. It seems reasonable to conclude that figural aftereffects and paracontrast are related but not equivalent phenomena.

Apparent motion and paracontrast. As indicated in Fig. 3d, apparent motion increases as the $I$ duration is increased from 30 to $100 \mathrm{msec}$ in Experiment 4. Duncan's test shows that this trend is significant beyond the .05 level. Paracontrast tends to decrease over the same range (Fig. $3 g$ ),

Table 2

The Results of Six $t$ tests Performed Between Corresponding Tasts Conditions in Experiments 1-6

\begin{tabular}{clll}
\hline Experiments & Variable & \multicolumn{1}{c}{ Task } & \multicolumn{1}{c}{$t$} \\
\hline 1 and 4 & I Duration & Figural Aftereffect & $3.087^{*}$ \\
& & Apparent Motion & 1.660 \\
2 and 5 & ISI & Figural Aftereffect & $2.176^{*}$ \\
& & Apparent Motion & $2.67^{*}$ \\
3 and 6 & IFD & Figural Aftereffect & $2.067^{*}$ \\
& & Apparent Motion & $2.185^{*}$ \\
\hline
\end{tabular}


but this effect does not approach significance. In Experiment 5, apparent motion decreases as the ISI is increased from 0 to $30 \mathrm{msec}$ (Fig. $3 \mathrm{e}$ ), whereas paracontrast increases (Fig. 3h). Duncan's tests indicate that both of these trends are significant. Both paracontrast and motion tend to decrease as the IFD is increased from 9 to $54 \mathrm{~min}$ in Experiment 6 (Figs. $3 \mathrm{f}$ and $3 i$ ). There are no significant differences between these trends. Thus, paracontrast and apparent motion are not the same phenomenon, although they appear very similar to each other.

\section{Motion in the 0 IFD Conditions}

The Ss did not show an apprecible change in their responses to the 0 IFD condition between Experiments 3 and 6. Although the amount of figural aftereffect and motion reported by the Ss increased, they still expressed confusion about the nature of the phenomena they were observing. The motion again appeared to be in the third dimension, but the Ss often failed to report it or the figural aftereffect. Paracontrast, of course, was quite high because the Ss failed to discriminate between the concentric circles. Although the motion appears to be a powerful effect for some Ss, the data do not allow us to make any further generalizations.

\section{GENERAL DISCUSSION}

The results of Experiments 4-6 tend to agree with the data presented by other researchers. Most Es have found that figural aftereffects produced by concentric figures are directly related to I duration, inversely related to the ISI, and are an inverted- $U$ function of the IFD (e.g., Oyama, 1956; Suto, 1961; Farné, 1965). Although Fehrer and Ganchrow (1963) and Obonai and Suzumura (1954) found inverted-U curves for changes in I duration and ISI, the data collected in the experiments reported here have their maxima and minima at the extreme values of the independent variables. In none of the cases where inverted-U functions were reported have they been shown to be statistically significant. This suggests that either the peaks occur at values not represented in these studies or that the peaks may be due to some very weak factors which were not involved in the experiments reported above.

The paracontrast data presented here are also compatible with previous findings. The shapes of paracontrast curves are usually very similar to those for metacontrast, but the effect is weaker (e.g., Kahneman, 1968). The data from Experiment 5 indicate that paracontrast is an inverted- $U$ function of the ISI with a maximum at about
30 msec. Most studies have shown that the combined duration of the I figure and the ISI, called the stimulus onset asynchrony or SOA, is the crucial variable under the conditions used in these experiments. The maximum paracontrast occurs at an SOA of $130 \mathrm{msec}$ in Experiment 5 (I duration $=100 \mathrm{msec} ;$ ISI $=30 \mathrm{msec}$ ). We would therefore expect a similar shape for the function in Experiment 4. These data do not show an inverted-U function of the SOA, but this is probably because there is no SOA value at $130 \mathrm{msec}$. Thus, the lack of an inverted- $U$ function represents an oversight rather than a contradiction of previous research. The data from Experiment 6 are also compatible with previous research which has shown that the amount of paracontrast decreases with the IFD (Kahneman, 1968).

The major discrepancies between the data collected here and in previous research are in the apparent-motion conditions. Weisstein and Growney (1969) reported an extensive series of experiments in which a number of temporal and luminance variables were systematically varied and the Ss judged apparent motion between adjacent squares. They found that apparent motion was not affected by changes in the IFD. Our results indicate that there is a significant reduction of motion with increases in the IFD. Weisstein and Growney also reported that apparent motion declined very slightly as the SOA was increased beyond $100 \mathrm{msec}$. The data from Experiments 2 and 5 show significant declines beyond SOAs of $100 \mathrm{msec}$.

At least part of the discrepancy is probably attributable to the different figures used in the experiments. Apparent motion is qualitatively different between adajcent squares and concentric circles. Our Ss may have been more sensitive to smaller changes in the amount of movement because of the figures. This hypothesis fails to explain why our motion data are similar to Kahneman's (1967) data, although he used the same figures as did Weisstein and Growney. Since both studies used within-Ss designs to measure apparent motion and metacontrast, part of the discrepancy may also result from different patterns of interaction between the tasks due to very subtle factors. Unfortunately, the precise explanation for these discrepancies will depend upon further evidence.

Finally, it appears that the peak of the apparent-motion curve occurs at an SOA of about $100 \mathrm{msec}$, as shown in Fig. 3d. This agrees with the results found both by Kahneman and by Weisstein and Growney and, in conjunction with the data on paracontrast reported above, suggests that the peaks of the apparent-motion and paracontrast curves occur at different SOAs. A more detailed study of the lower portion of the SOA range is necessary to definitely establish this phenomenon.

\section{SUMMARY AND CONCLUSIONS}

The results of these experiments support an unparsimonious view of figural aftereffects, apparent motion, and paracontrast. The data, with no extrapolations or interpolations, indicate that figural-aftereffect functions are significantly different from both apparent-motion and paracontrast functions when the duration of the I figure and the IFD are varied and that the paracontrast function is significantly different from the figural-aftereffect and apparent-motion functions when the ISI is varied. With interpolations and extrapolations, it seems likely that both apparent motion and paracontrast are inverted- $U$ functions of the SOA but that the peak of the motion curve occurs at an SOA of about $100 \mathrm{msec}$, where the peak of the paracontrast curve occurs at an SOA of about $130 \mathrm{msec}$. Figural aftereffects are directly related to ISI and thus are not adequately described by the concept of SOA, at least under the conditions of these experiments. Further, apparent motion and paracontrast are inversely related to the IFD from 9 to $54 \mathrm{~min}$, whereas figural aftereffects are an inverted-U function. Thus, the results from the six experiments indicate that these three phenomena cannot be conceived of as a single entity.

One of the important conclusions from these data is that there is a strong interaction between figural-aftereffect and apparent-motion tasks. It is clear that asking an $S$ to evaluate both phenomena produced a response bias, even though he was asked to rate the two phenomena on different trials. If the $S$ is aware of both phenomena, this is apparently enough to create serious distortions in the functions. Researchers should consider using between-Ss designs in studies comparing different dependent variables unless they have demonstrated that the effects they are measuring are independent.

Finally, there are several implications of these data for the analysis of feature analyzers in the human visual system. Weisstein (1968) has suggested that masking may be used to study human feature analyzers. Presumably, the thresholds of such analyzers are raised through continued use, and this may be reflected in the "dimming" or erasure of the $T$ figure. By varying temporal, 
spatial, and luminance parameters of the stimuli, the behavior of the analyzers can be inferred from the masking functions. Weisstein has also suggested that figural aftereffects, which presumably represent distortions in the outputs from feature analyzers, do not provide the same information because they confound several different sets of anaiyzers. Over (1971) has responded by pointing out that some of the functions relating independent variables to each phenomenon are very similar and that there is no logical reason for using masking rather than aftereffects for isolating and studying feature analyzers.

The data from the experiments reported here indicate that figural aftereffects, apparent motion, and paracontrast masking are not equivalent. Thus, all three dependent variables contain unique information. Given our relative ignorance of the nature of the feature analyzers in the human visual system (cf. Brindley, 1970), it would seem dangerous to use one or the other phenomenon exclusively as a basis for models of human vision. Rather, more emphasis should be placed on joint experiments in which different dependent measures are used under equivalent conditions (but with different $S s$ ) in order to specify the state of the $S$ more fully. Such procedures would provide more accurate profiles of the feature analyzers and their operation.

\section{REFERENCES}

BEVAN, W., JR. The influence of figural after-effects upon visual intensity thresholds. Journal of General Psychology, 1951, 45, 189-207.

BRINDLEY, G. S. Physiology of the retina and visual pathway. (2nd ed.) Baltimore: Williams \& Wilkins, 1970.

CHRISTMAN, R. J. Figural after-effects utilizing apparent movement as inspection-figure. American Journal of Psychology, 1953, 66, 66-72.

DETHERIDGE, B. H., \& BITTERMAN, M. E. The effect of satiation on stroboscopic movement. American Journal of Psychology, 1952, 25, 108-109.

FARNE, M. Figural after-effects with short exposure-time. An interpretation of the so-called "Subliminal perception." Psychologische Forschung. 1965, 28, 519-534.

FEHRER, E., \& GANCHROW, D. Effects of exposure variables on figural aftereffects under tachistoscopic presentation.
Journal of Experimental Psychology, $1963,66,506-513$

GRAHAM, C. H. Perception of movement. In C. H. Graham (Ed.), Visual perception. New York: Wiley, 1966. Pp. 575-588.

HIGGINSON, G. D. The visual apprehension of movement under successive retinal excitations. American Journal of Psychology, 1926, 37,63-115.

HOWARD, R. B. Neurophysiological models of figural aftereffects and visual illusions. Psychonomic Monograph Supplements, 4(3, Whole No. 51), 57-72.

HOWARD, R. B., \& EVANS, G. W. Some evidence for the size-modification theories of illusions. Psychonomic Science, 1971, 23, 129-131.

KAHNEMAN, D. An onset-onset law for one case of apparent motion and metacontrast. Perception \& Psychophysics, 1967, 2, 577-583.

KAHNEMAN, D. Method, findings, and theory in studies of visual masking Psychological Bulletin, 1968, 70 , 404-425.

KÖHLER, W. Dynamics in psychology. New York: Liveright, 1940 .

KÖHLER, W. Unsolved problems in the field of figural after-effects. Psychological Record, 1965, 15, 63-83.

KÖHLER, W., \& WALLACH, H. Figural aftereffects: An investigation of visual processes. Proceedings of the American Philosophical Society, 1944, 88, 269-357.

MCCONNELL, R. F, Visual movement under simultaneous excitations with initial and terminal overlap. Journal of Experimental Psychology, 1927, 10 227-246.

MOTOKAWA, K., NAKAGAWA, D., \& KOHATA, T. Figural after-effects and retinal induction. Journal of General Psychology, 1957, 57, 121-135.

NEFF, W. S. A critical investigation of the visual apprehension of movement. American Journal of Psychology, 196, 68, 1-2.

NAZAWA, S. An experimental study on figural after-effect by the measurement of field strength. Japanese Psychological Research, 1956, 3, 15-24.

OBONAI, T., \& SUZUMURA, K Contributions to the study of psychophysiological induction (43). The characteristics of successive induction during periods immediately following retinal stimulation. Japanese Psychological Research, 1954, 1, 45-54. OVER, $R$. Comparison of normalization theory and neural enhancement explanation of negative aftereffect. Psychological Bulletin, 1971, 75, 225-243.

OYAMA, $T$. Temporal and spatial factors in figural after-effects. Japanese Psychological Research, 1956, 3, 25-36.

SHAPIRO, M. B. A preliminary investigation of the effects of continuous stimulation on the perception of "apparent motion." British Journal of Psy chology, 1954, 45, 58-67.

SUTO Y Comparative study of assimilation-contrast illusion, figural aftereffects, and time-error for extents of circles and line stimuli. Japanese
Psychological Research, 1961, 3, 1-16.

WEISSTEIN, N. What the frog's eye tells the human brain: Single cell analyzers in the human visual system. Psychological Bulletin, 1969, 72, 157-176.

WEISSTEIN, N., \& GROWNEY, R. L. A pparent movement and metacontrast: A note on Kahneman's formulation. Perception \& Psychophysics, 1969, 5, 321-328.

WINER, B. J. Statistical principles in experimental design. New York: McGraw-Hill, 1971.

\section{NOTES}

1. Since the terminology used here is necessarily eclectic, the reader may find the following definitions of some value. The term figural aftereffects will refer to changes in the location of a visual figure's contours resulting from the presence of another figure presented prior to it in time. The first figure, which presumably caused the distortion, will be called the inspection (I) figure. The second figure, whose contours are distorted, will be called the test $(T)$ figure. In order to estimate the magnitude of the figural aftereffect, a comparison (C) figure is presented simultaneously with the $T$ figure in such a way that it is presumably unaffected by the I figure. In the experiments reported here, the figures are concentric circles. Thus, changes in the locations of the $T$ figure's contours result in a change in its size. For a fuller discussion of the roles of location and size distortions in figural aftereffects and illusions, see Howard (1971) and Howard and Evans (1971)

The independent variables used in the experiments have been given their most common names. The interstimulus interval (ISI) refers to the interval from the offset of the I figure to the onset of the $T$ figure. The interfigural distance (IFD) refers to the spatial separation of the $I$ and $T$ contours. The stimulus-onset asynchrony (SOA) refers to the interval from the onset of the I figure to the onset of the $T$ figure. Thus, it includes both the duration of the I figure and the ISI.

In order to avoid semantic arguments, apparent motion refers to any form of motion between two stationary objects. Finer distinctions between alpha, beta, delta, gamma, and phi motion are not made here because they represent phenomenological categories which may be invalid. Paracontrast refers to the weakening of the percept of the second of two figures by the first. Metacontrast is the weakening of the first by the second. The term masking is used to refer to both meta- and paracontrast phenomena. In keeping with the figural aftereffect portion of the article, the figures are referred to as the $I$ and $T$ figures, respectively, although this is not the traditional terminology used in motion or masking experiments.

2. A complete description of the design is available from the author upon request.

(Received for publication August 2, 1971 ; revision received June 27,1972 .) 